\title{
Is there a therapeutic window for pentoxifylline after the onset of acute pancreatitis? ${ }^{1}$
}

\author{
Existe uma janela terapêutica para a pentoxifilina após o início da pancreatite aguda?
}

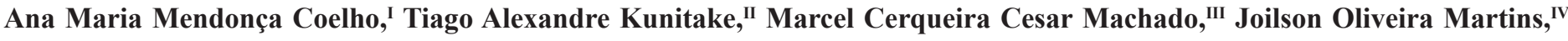

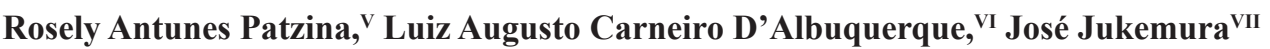 \\ I PhD, Laboratory of Liver Transplantation and Experimental Surgery (LIM/37), Department of Gastroenterology, Medical School, University of São \\ Paulo, São Paulo, Brazil. Performed biochemical analysis, statistical evaluation, and manuscript writing.

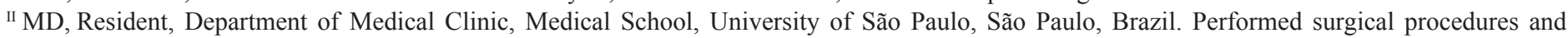 \\ collection of data. \\ III MD, PhD, Department of Gastroenterology, Medical School, University of São Paulo, São Paulo, Brazil. Critical revision of the study. \\ ${ }^{\text {IV }} \mathrm{PhD}$, Department of Clinical and Toxicological Analyses, Faculty of Pharmaceutical Sciences, University of Sao Paulo, Sao Paulo, Brazil. Manuscript \\ writing and critical revision. \\ ${ }^{\mathrm{v}} \mathrm{MD}, \mathrm{PhD}$, Department of Pathology, Medical School, University of São Paulo, São Paulo, Brazil. Performed histological analysis. \\ ${ }^{\text {VI } C h a i r m a n ~ a n d ~ H e a d, ~ D i g e s t i v e ~ T r a c t ~ T r a n s p l a n t a n t i o n ~ D i v i s i o n, ~ D e p a r t m e n t ~ o f ~ G a s t r o e n t e r o l o g y, ~ M e d i c a l ~ S c h o o l, ~ U n i v e r s i t y ~ o f ~ S a ̃ o ~ P a u l o, ~ S a ̃ o ~}$ \\ Paulo, Brazil. Critical revision of the study.

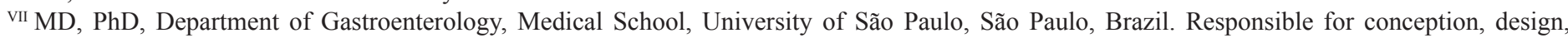 \\ intellectual and scientific content of the study.
}

\begin{abstract}
PURPOSE: To investigate the effects of pentoxifylline (PTX) in experimental acute pancreatitis (AP) starting drug administration after the induction of the disease.

METHODS: One hundred male Wistar rats were submitted to taurocholate-induced AP and divided into three groups: Group Sham: sham-operated rats, Group Saline: AP plus saline solution, and Group PTX: AP plus PTX. Saline solution and PTX were administered 1 hour after induction of AP. At 3 hours after AP induction, peritoneal levels of tumor necrosis factor (TNF)- $\alpha$, and serum levels of interleukin (IL)-6 and IL-10 levels were assayed by Enzyme-Linked Immunosorbent Assay (ELISA). Determinations of lung myeloperoxidase activity (MPO), histological analysis of lung and pancreas, and mortality study were performed.

RESULTS: PTX administration 1 hour after induction of AP caused a significant decrease in peritoneal levels of TNF- $\alpha$ and in serum levels of IL-6 and IL-10 when compared to the saline group. There were no differences in lung MPO activity between the two groups with AP. A decrease in mortality was observed in the PTX treatment compared to the saline group.

CONCLUSIONS: Administration of PTX after the onset of AP decreased the systemic levels of proinflammatory cytokines, raising the possibility that there is an early therapeutic window for PTX after the initiation of AP.
\end{abstract}

Key words: Acute Pancreatitis; Pentoxifylline; Inflammation; Cytokines; Systemic Inflammatory Response

\section{RESUMO}

OBJETIVO: Investigar os efeitos da pentoxifilina (PTX) na pancreatite aguda (PA) experimental administrando a droga após a indução da doença.

MÉTODOS: Cem ratos machos Wistar foram submetidos à indução da PA através da infusão de taurocolato de sódio e divididos em três grupos: Grupo Sham: sham-operated ratos, Grupo Salina: AP e solução salina, e Grupo PTX: AP e PTX. Solução salina e PTX foram administradas 1 hora após a indução da PA. Três horas após indução da PA os níveis de fator de necrose tumoral (TNF)- $\alpha$ no líquido peritoneal e os níveis séricos de interleucina (IL)-6 e IL-10 foram analisados pelo método de Enzima Imunoensaio (ELISA). A atividade da mieloperoxidase (MPO) foi analisada no pulmão e foram realizadas análises histológicas do pulmão e pâncreas, além do estudo da mortalidade.

RESULTADOS: A administração de PTX 1 hora após a indução da PA reduziu significativamente os níveis de TNF- $\alpha$ peritoneal e os níveis séricos de IL-6 e IL-10 quando comparado ao grupo salina. Redução na mortalidade foi observado após o tratamento com PTX comparado ao grupo salina.

CONCLUSÃO: A administração de PTX após a indução da PA diminuiu os níveis sistêmicos de citocinas pró-inflamatórias, sugerindo a possibilidade de que existe uma janela terapêutica para PTX após o início do PA.

Descritores: Pancreatite Aguda; Pentoxifilina; Inflamação; Citocinas; Resposta Inflamatória Sistêmica 


\section{Introduction}

Severe acute pancreatitis (AP) is a disease related to high morbidity and mortality. It is associated with an increase in inflammatory mediators that induce the systemic inflammatory response syndrome (SIRS) and can lead to distant organ dysfunction ${ }^{1,2}$.

Serum levels of proinflammatory cytokines such as interleukin (IL)-1, IL-6, IL-8, tumor necrosis factor (TNF)- $\alpha$, platelet activating factor (PAF), and nitric oxide (NO) increase early during the course of AP and these levels directly correlate with the severity of pancreatic inflammation ${ }^{3}$. In addition, TNF- $\alpha$, a cytokine produced mainly by activated monocytes and macrophages, seems to play an important role as a mediator of inflammation and cellular immune responses in AP through the initiation of a cytokine cascade ${ }^{4,5}$.

Administration of agents that antagonize or diminish the production of TNF- $\alpha$ is associated with a decrease of the systemic effects of $\mathrm{AP}^{6-10}$. Pentoxifylline (PTX), a methylxanthine derivative, exhibits marked anti-inflammatory properties through the inhibition of nuclear factor (NF)- $\kappa \mathrm{B}$ and consequently blocks TNF- $\alpha$ production ${ }^{11-12}$.

Treatment of AP with PTX has shown to be beneficial in the experimental management of this disease ${ }^{13-16}$. Studies from our group have demonstrated that administration of PTX in rats with taurocholic acid-induced AP reduced local and systemic inflammatory responses and decreased pancreatic infection and mortality rate $^{16}$. However, administration of this drug in these studies was done at the time of AP induction, which is unrealistic in a clinical setting where patients already have developed systemic inflammation.

In the present study we attempt to elucidate the presence of an early therapeutic window for PTX as an anti-inflammatory drug after the onset of AP in an experimental animal model.

\section{Methods}

The experimental protocol was approved by the Ethics Commitee for Animal Research from the Medical School of São Paulo University. All animals received care in accordance with the Guide for the Care and Use of Laboratory.

One hundred adult male Wistar rats weighing 240 to $260 \mathrm{~g}$, housed in individual cages in a 12-hour dark lightcontrolled environment, were used for the experimental protocol. Temperature was kept at 21 to $22^{\circ} \mathrm{C}$ and all rats were fed with a standard rat chow and ad libitum water.

\section{Reagents}

All chemical reagents were purchased from SigmaAldrich (St. Louis, MO). TNF- $\alpha$, IL-6 and IL-10 were assayed with corresponding kits from BioSource International (Camarillo, LA, Calif).

\section{Induction of acute pancreatitis}

Surgical anesthesia was induced with ketamine chloride $50 \mathrm{mg} / \mathrm{ml}(0.2 \mathrm{ml} / 100 \mathrm{~g}$ body weight) (Ketalar; Parke-Davis, São Paulo, Brazil). AP was induced in anesthetized rats by retrograde intraductal injection of $0.5 \mathrm{ml}$ of $2.5 \%(\mathrm{w} / \mathrm{v})$ sodium taurocholate in $0.9 \%(\mathrm{w} / \mathrm{v}) \mathrm{NaCl}$ into the main pancreatic duct for 1 minute at a constant rate using an infusion pump (KD Scientific, Holliston, MA). The proximal part of the hepatic duct was clamped during the injection ${ }^{17,18}$.

\section{Experimental groups}

Animals were randomized to the following experimental groups:

Group Sham: twenty sham-operated rats submitted to operative procedure without induction of AP.

Group Saline: forty rats submitted to AP plus intraperitoneal administration of saline solution.

Group PTX: forty rats submitted to AP plus intraperitoneal administration of PTX

\section{Pentoxifylline and saline administration}

Intraperitoneal administration of PTX, at $25 \mathrm{mg} / \mathrm{kg}$ of animal weight $(1.25 \mathrm{ml} / \mathrm{Kg})$ (Trental ${ }^{\mathrm{TM}}$, Sanofi Aventis Pharma, São Paulo, Brazil), was performed one hour after induction of AP and the same dose was repeated after 12 hours.

Intraperitoneal administration of saline solution, at 1.25 $\mathrm{ml} / \mathrm{kg}$ of animal weight, was performed one hour after AP induction and was repeated after 12 hours. In previous experimental studies we have demonstrated that in this rat model of AP using sodium taurocholate the highest levels of inflammatory cytokines occurs between 2 and $4 \mathrm{~h}$ after AP induction therefore 1 hour is an appropriate length of time to start the treatment ${ }^{16}$.

\section{Sample Preparation}

At 3 hours after AP induction, animals were anesthetized for blood sampling through cardiac puncture and killed by exsanguination. Peritoneal levels of TNF- $\alpha$ and serum levels of IL-6 and IL-10 were assayed by a solid-phase sandwich enzymelinked immune absorbent assay (ELISA). Lung myeloperoxidase activity (MPO) was analyzed in lung homogenates. A portion of 
the pancreas and lungs were fixed in $10 \%(\mathrm{v} / \mathrm{v})$ buffered formalin for histological analysis.

\section{Lung myeloperoxidase activity}

MPO activity was used as an indicator of neutrophils infiltration into tissues. Samples of lung tissue were homogenized with a Polytron homogenizer using a homogenization buffer containing $0.5 \%$ of hexadecyltrimethyl ammonium bromide, 5 $\mathrm{mmol} / \mathrm{L}$ EDTA, and $50 \mathrm{mmol} / \mathrm{L}$ phosphate at $\mathrm{pH}$ 6.0. Homogenized samples were sonicated and centrifuged (3.000xg, 30 minutes) at $4^{\circ} \mathrm{C}$. MPO activity in the supernatant was assayed by measuring the change in $\mathrm{A}_{460}$ resulting from the decomposition of $\mathrm{H}_{2} \mathrm{O}_{2}$ in the presence of O-dianisidine. Results were expressed as optical density (OD) at $460 \mathrm{~mm}^{19,20}$.

\section{Histological analysis}

Fragments of pancreas and lungs were harvested, fixed, embedded in paraffin, sectioned, and stained with hematoxylin and eosin for light microscopy. Histological evaluation of the pancreas and lung sections was performed by the same pathologist in a blinded way.

Severity of necrotizing pancreatitis was determined by a scoring system that includes the graded assessment of pancreatic edema, inflammatory infiltration, pancreatic necrosis, pancreatic hemorrhage, and extrapancreatic fat necrosis, on a scale of 0 to $4^{21}$

Lung injury was assessed using a 0 to 4 scoring system to evaluate the following lesions: intersticial cellular infiltration, intra-alveolar neutrophilic infiltration, intersticial and alveolar edema, hyaline membrane formation, capillary congestion, type II pneumocyte hyperplasia and intra-alveolar hemorrhage ${ }^{22}$.

\section{Mortality study}

Thirty animals from each group with AP were observed for a period of 7 days after AP induction to evaluate the mortality rate. These animals were maintained in individual cages with access to regular rat chow, and received PTX or saline solution as determined by the experimental protocol.

\section{Statistical analysis}

The groups were compared using ANOVA test and results are presented as mean values \pm SEM. Histological analysis was performed by the Mann-Whitney test. Survival was evaluated using the Kaplan-Meier method and was analyzed for significance with the log-rank test (Cox-Mantel) and Wilcoxon test. The level of $\mathrm{P}<0.05$ was considered statistically significant. The data were analyzed using Graphpad Prism ${ }^{\circledR} 4.0$ software (San Diego, California).

\section{Results}

\section{PTX effect on systemic inflammation in AP}

We observed formation of ascitic fluid in the AP groups when compared with animals of the sham-operated group. PTX administration significantly reduced TNF- $\alpha$ levels in peritoneal fluid compared to the saline group ( $\mathrm{p}=0.04$ ) (Figure 1A).

Levels of IL-6 and IL-10 were undetectable in the serum of sham-operated animals. A significant decrease in IL-6 $(p=0.027)$ and IL-10 ( $\mathrm{p}=0.037)$ levels was observed after PTX administration when compared to the saline group (Figures $1 \mathrm{~B}$ and $1 \mathrm{C}$ ).

Together, these data indicate a reduction of systemic inflammation after PTX administration in AP. 
A

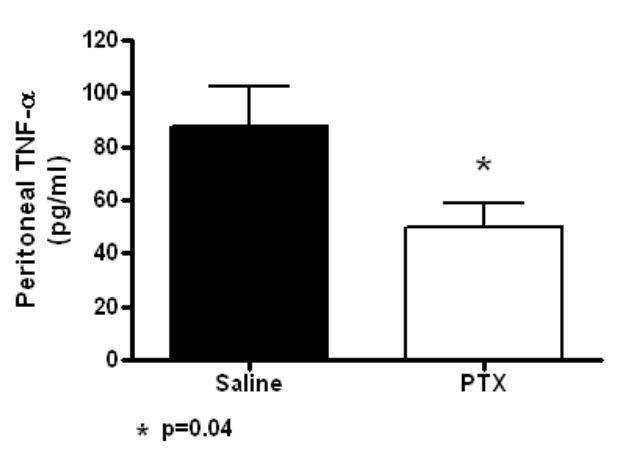

B

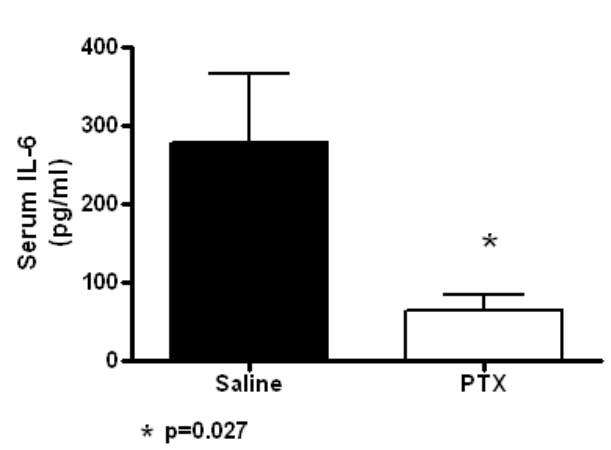

C

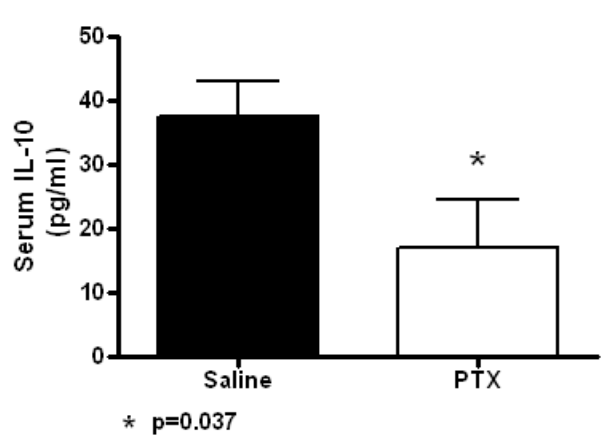

FIGURE 1: Inflammatory cytokines levels after AP induction. AP was induced in rats by intraductal injection of $0.5 \mathrm{ml}$ of $2.5 \%$ taurocholic acid. Saline group received saline solution administration 1 hour after AP induction and PTX group received PTX treatment 1 hour after AP induction. Concentration of peritoneal TNF- $\alpha$ (A); serum IL-6 levels (B); and serum IL-10 (C). Data are expressed as mean \pm SEM of 10 animals per group. ${ }^{*} \mathrm{p}<0.05$

\section{Serum IL-6/IL-10 ratio}

The serum IL-6/IL-10 ratio was calculated to determine possible imbalances in serum inflammatory activity. The serum IL-6/IL-10 ratios were 7.3 in saline AP rats, and 3.8 in AP rats treated with PTX. Accordingly, results indicated that there was a prevalence of anti-inflammatory activity in PTX treated rats compared with the saline group.

\section{PTX effect on lung MPO activity}

To assess lung inflammation by neutrophil infiltration, MPO activity was measured. At 3 hours after AP induction, MPO activity was increased in the pulmonary tissue. There was no statistical difference between the PTX and saline treatments after AP induction (Figure 2). However, the results show a trend toward a reduction in lung inflammation in the PTX group $(\mathrm{p}=0.094)$.

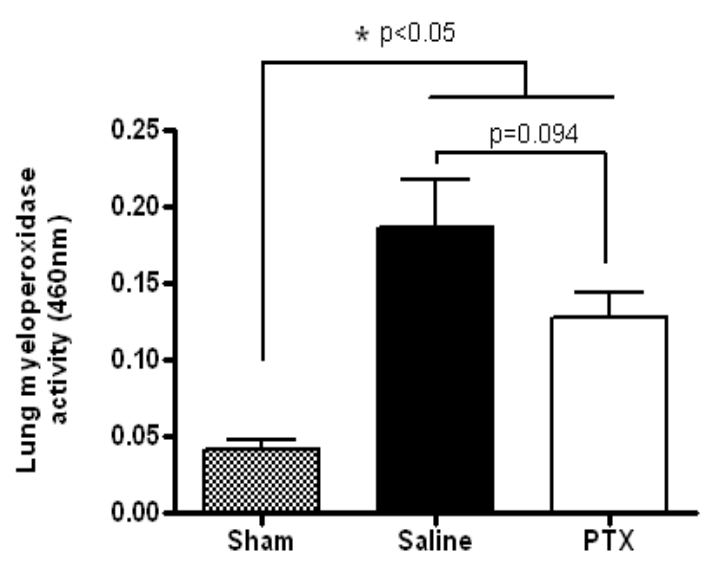

FIGURE 2: Myeloperoxidase activitiy in the lung after AP induction. $\mathrm{AP}$ was induced in rats by intraductal injection of $0.5 \mathrm{ml}$ of $2.5 \%$ taurocholic acid. Saline group received saline solution administration 1 hour after AP induction and PTX group received PTX treatment 1 hour after $\mathrm{AP}$ induction. Data are expressed as mean \pm SEM of 10 animals per group. $* \mathrm{p}<0.05$ comparing sham-operated group with the AP groups; $\mathrm{p}=0.094$ comparing PTX and saline groups

\section{PTX effect on lung and pancreatic histology}

We also evaluated the severity of pancreatitis by histological analysis of lung and pancreatic lesions. Histological scores found in animals with AP compared to the sham-operated group, did not differ between the PTX and saline treatments after AP induction.

\section{PTX effect on mortality study}

After AP induction, mortality rate was evaluated. A decrease in mortality was observed in the PTX treatment $(5 / 30$, $17 \%)$ compared to the saline group $(11 / 30,37 \%),(p=0.07)$ (Figure 3 ). There was no mortality in the sham-operated group (data not shown). 


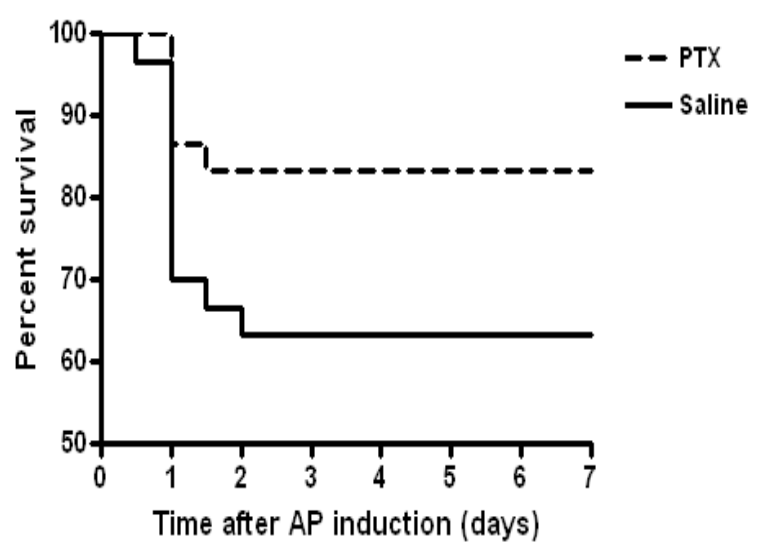

FIGURE 3: Animal survival. AP was induced in rats by intraductal injection of $0.5 \mathrm{ml}$ of $2.5 \%$ taurocholic acid. Saline group received saline solution administration 1 hour after AP induction and PTX group received PTX treatment 1 hour after AP induction. The Kaplan-Meier curve for the two groups is shown. Mortality was observed for 7 days after AP induction $(\mathrm{p}=0.07)$

\section{Discussion}

Acute pancreatitis involves a complex cascade of events, including pancreatic inflammation, destruction of pancreatic tissue, and a systemic inflammatory response, mediated by IL-1, IL-6, IL-8, TNF- $\alpha$, NO, reactive oxygen species, and PAF, which are markedly increased early after the onset of the disease.

The levels of proinflammatory cytokines seem to correlate with morbidity and mortality associated with $\mathrm{AP}^{23}$.The use of drugs that block the activation of these cytokines could attenuate the severity of AP. Among these drugs, PTX exhibits marked anti-inflammatory properties through the inhibition of TNF- $\alpha$ production after shock, acute endotoxemia, and cerebral ischemia in rats $11,24,25$. The mitogen-activated protein kinases (MAPK) and NF-kB are integral components of many signal transduction pathways. Hofken et al. ${ }^{26}$ and De Campos et al. ${ }^{14}$ have demonstrated the role of MAPK activation in AP-induced acute lung injury (ALI) with the observations that MAPKs are activated early in the course of AP and inhibition of their phosphorylation can ameliorate the effects of the disease, indicating that PTX is capable of attenuating key signaling events in the inflammatory cascade. In addition, they observed a reduction in the phosphorylation of cytoplasmic I-kB and nuclear p65-NF-kB, which its activity in both the pancreas and distant organs has been shown to correlate with degree of illness, whereas inhibitors of NF-kB have been proven effective in reducing systemic inflammation in severe $\mathrm{AP}^{14,26}$. The suggestion is that PTX regulates cytokines transcription and neutrophil recruitment, at least in part, via MAPKs and NF-кB signaling pathway.

Treatment of AP with PTX has shown to be beneficial in the experimental management of this disease, however administration of this drug in these studies was done at the time of AP induction ${ }^{13-16}$. In an experimental model of severe AP, evaluating the effect of administration of PTX after the onset of $\mathrm{AP}$, no changes of the hemodynamic parameters and mortality rate were observed however, in this study inflammatory parameters were not evaluated ${ }^{27}$.

Therefore, in the present study, and according to clinical practice, we utilized treatment with PTX after the onset of AP and observed reduction of peritoneal and serum levels of proinflammatory cytokines.

As has been previously described, TNF- $\alpha$ is considered the trigger of an inflammatory cascade in AP because it induces the synthesis and release of other cytokines ${ }^{4}$. Some authors have shown the beneficial effect of the pretreatment of AP through the inhibition of TNF- $\alpha$ by using an antibody against TNF- $\alpha^{6,7}$. Our group has also demonstrated the beneficial effect o PTX administration at the time of AP induction ${ }^{16}$. In the present study we observed that PTX administered after the onset of AP effectively inhibited the production of TNF- $\alpha$ and IL- 6 , which are AP markers and whose levels correlate with the severity of the disease. Inhibition of TNF- $\alpha$ production, at least in part, via MAPKs and NF- $\kappa$ B signaling pathway may explain the marked PTX antiinflammatory properties ${ }^{11,24,25}$. In addition, PTX increases blood cell deformability, decreases platelet aggregation, lowers blood viscosity, and reduces thrombus formation, therefore improving microvascular flow ${ }^{28}$. In addition, PTX treated rats exhibited a prevalence of anti-inflammatory activity compared with the saline AP group, as indicated by serum IL-6/IL-10 ratios. The suggestion is that the proper production/release of proinflammatory and antiinflammatory cytokines might be an importante effect of PTX treatment.

Pulmonary complications are the most critical distant event in severe AP, being the most common cause of death during the initial phase of the disease ${ }^{29}$. Previously, it was reported that PTX administration at the time of AP induction was capable of attenuating pulmonary inflammation and histological lung injury in a model of severe $\mathrm{AP}^{14}$. In the present study, we also observed a clear tendency to reduction of pulmonary neutrophil sequestration, evaluated by MPO levels, in PTX treatment compared to the saline group.

Histological scores in lung and pancreas from animals with AP, compared to the sham-operated group, did not differ between the PTX and saline treatments after AP induction. The drug 
may be effective however, to ameliorate histological parameters in mild edematous pancreatitis (13) or when administration of this drug is done at the time of AP induction ${ }^{16}$.

To further evaluate the effects of PTX treatment, we also studied mortality rates after attenuating systemic levels of proinflammatory cytokines. The results showed a reduction of mortality with PTX treatment compared to the saline group.

In conclusion, this is the first study that demonstrates the potential therapeutic effects of PTX administered after severe AP induction. Reduction of systemic levels of proinflammatory cytokines by this drug might be useful in the clinical practice for the management of early phase AP. In fact, clinical studies have shown that inflammatory mediators reach the highest serum concentration on day three after the onset of $\mathrm{AP}^{30}$. Further studies are still needed to fully understand the effects of PTX on proinflammatory mediators and other aspects of severe AP. Our observations raise the hypothesis that an early therapeutic window exits for PTX treatment after the onset of AP, which should be object of future studies.

Acknowledgment: We thank Sandra Sampietre and Nilza Molan for technical assistance to this study.

\section{References}

1. Pitchumoni CS, Patel NM, Shah P: Factors influencing mortality in acute pancreatitis: can we alter them? J Clin Gastroenterol. 2005;39:798-814.

2. Frossard JL, Steer ML, Pastor CM. Acute pancreatitis. Lancet 2008;371:143-52.

3. Bhatia M, Wong FL, Cao Y, Lau HY, Huang J, Puneet P, Chevali L. Pathophysiology of acute pancreatitis. Pancreatology. 2005;5:13244.

4. Norman J. The role of cytokines in the pathogenesis of acute pancreatitis. Am J Surg.1998; 175:76-83.

5. Malleo G, Mazzon E, Siriwardena AK, Cuzzocrea S. Role of tumor necrosis factor-alpha in acute pancreatitis: from biological basis to clinical evidence. Shock. 2007;28:130-40.

6. Malleo G, Mazzon E, Genovese T, Di Paola R, Muià C, Centorrino T, Siriwardena AK, Cuzzocrea S. Etanercept attenuates the development of cerulein-induced acute pancreatitis in mice: a comparison with TNF-alpha genetic deletion. Shock. 2007;27:54251.

7. Yilmaz M, Tekekoglu S, Herek O, Ozmen O, Sahinduran S, Buyukoglu T Ameliorative effect of adalimumab on experimentally induced acute pancreatitis in rats. Pancreas. 2010;39:1238-42.

8. Machado MC, Coelho AM, Martins JO, Sampietre SN, Molan NA, Patzina RA, Machado MA, Jancar S. CO2 abdominal insufflation decreases local and systemic inflammatory response in experimental acute pancreatitis. Pancreas. 2010;39:175-81.

9. Souza LJ, Coelho AM, Sampietre SN, Martins JO, Cunha JE, Machado MC. Anti-inflammatory effects of peritoneal lavage in acute pancreatitis. Pancreas.2010;39:1180-84.

10. Coelho AM, Jukemura J, Sampietre SN, Martins JO, Molan NA, Patzina RA, Lindkvist B, Jancar S, Cunha JE, D'Albuquerque LA,
Machado MC. Mechanisms of the beneficial effect of hypertonic saline solution in acute pancreatitis. Shock. 2010;34:502-7.

11. Coimbra R, Melbostad H, Hoyt DB. Effects of phosphodiestarase inhibition on the inflammatory response after shock: role of pentoxifylline. J Trauma. 2004;56:442-49.

12. Deree J, Martins JO, Melbostad H, Loomis WH, Coimbra R. Insights into the regulation of TNF- $\alpha$ production in human mononuclear cells: the effects of non-specific phosphodiesterase inhibition. Clinics. 2008;63:321-8.

13. Marton J, Farkas G, Takacs T, Nagy Z, Szasz Z, Varga J,Jarmay $\mathrm{K}$, Balogh A, Lonovics J. Beneficial effects of pentoxifylline treatment of experimental acute pancreatitis in rats. Res Exp Med. 1998;197:293-9.

14. de Campos T, Deree J, Martins JO, Loomis WH, Shenvi E, Putnam JG, Loomis WH, Wolf P,. Coimbra R. Pentoxifylline attenuates pulmonary inflammation and neutrophil activation in experimental acute pancreatitis. Pancreas. 2008;37:42-9.

15. Sandoval J, Escobar J, Pereda J, Sacilotto N, Rodriguez JL, Sabater L, Aparisi L, Franco L, López-Rodas G, Sastre J. Pentoxifylline prevents loss of PP2A phosphatase activity and recruitment of histone acetyltransferases to proinflammatory genes in acute pancreatitis. J Pharmacol Exp Ther. 2009;331:609-7.

16. Matheus AS, Coelho AM, Sampietre S, Jukemura J, Patzina RA, Cunha JE, Machado MC. Do the effects of pentoxifylline on the inflammatory process and pancreatic infection justify its use in acute pancreatitis? Pancreatology. 2009;9:687-93.

17. Storck G. Fat necrosis in acute pancreatitis. Morphological and chemical studies in the rat. Acta Chir Scand. 1971;417:1-36.

18. Lankisch PG, Ihse I. Bile-induced acute experimental pancreatitis. Scand J Gastroenterol. 1987;22:257-60.

19. Goldblum SE, Wu KM, Jay M. Lung myeloperoxidase as a measure of pulmonary leukostasis in rabbits. J Appl Physiol. 1985;59:197885.

20. Warren JS, Yabroff KR, Mandel DM, Johnson KJ, Ward PA. Role of $\mathrm{O}_{2}$ - in the neutrophil recruitment into sites of dermal and pulmonary vasculitis. Free Radic Biol Med. 1990;8:163-72.

21. Schmidt J, Rattner DW, Lewandrowski R, Compton CC, Mandavilli U, Knoefel WT, Warshaw AL. A better model of acute pancreatitis for evaluating therapy. Ann Surg. 1992;215:44-56.

22. Simons RK, Maier RV, Chi EY. Pulmonary effects of continuous endotoxin infusion in the rat. Circ Shock. 1991;33:233-43.

23. Hirota M, Nozawa F, Okabe A, Shibata M, Beppu T, Shimada S, Egami H, Yamaguchi Y, Ikei S, Okajima T, Okamoto K, Ogawa. Relationship between plasma cytokine concentration and multiple organ failure in patients with acute pancreatitis. Pancreas. 2000;21:141-6.

24. Coimbra R, Melbostad H, Loomis W, Tobar M, Hoyt DB. Phosphodiesterase inhibition decreases nuclear factor-kappaB activation and shifts the cytokine response toward anti-inflammatory activity in acute endotoxemia. J Trauma . 2005;9:575-82.

25. Vakili A, Mojarrad S, Akhavan MM, Rashidy-Pour A. Pentoxifylline attenuates TNF- $\alpha$ protein levels and brain edema following temporary focal cerebral ischemia in rats. Brain Res. 2011;1377:119-25.

26. Hofken T, Keller N, Fleischer F, Göke B, Wagner AC. Map kinase phosphatases (MKP's) are early responsive genes during induction of cerulein hyperstimulation pancreatitis. Biochem Biophys Res Commun. 2000;276:680-5.

27. Bassi DG, Foitzik T, Rattner DW, Lewandrowski K, Warshaw AL, Fernández-del Castillo C. Failure of pentoxifylline to ameliorate severe acute pancreatitis in the rat: results of a prospective, randomized, controlled study. Crit Care Med. 1994;22:1960-3.

28. Huh PW, Kotasek D, Jacob HS, Vercellotti GM, Hammerschmidt DE. Mechanism of action of pentoxifylline in peripheral vascular 
disease: inhibition of platelet and granulocyte responsiveness. Clin Res. 1985;33:866-78.

29. Zhou MT, Chen CS, Chen BC, Zhang QY, Andersson R. Acute lung injury and ARDS in acute pancreatitis: mechanisms and potential intervention. World J Gastroenterol. 2010;16:2094-9.

30. Mayer J, Rau B, Gansauge F, Beger HG. Inflammatory mediators in human acute pancreatitis: clinical and pathophysiological implications. Gut. 2000;47:546-52.

\section{Correspondence}

Ana Maria Mendonça Coelho

Departmento de Gastroenterologia

Universidade de São Paulo

R. João Moura, 690/41

05412-001 São Paulo, SP, Brazil

Tel(5511)3061-8326, FAX(5511) 3061-7270

amcoelho@usp.br

Received: February 16, 2012

Review: April 18, 2012

Accepted: May 21, 2012

Conflict of interest: none

Financial source: São Paulo Research Foundation (FAPESP)

${ }^{1}$ Research performed at Laboratory of Liver Transplantation and Experimental Surgery (LIM/37), Department of Gastroenterology, Medical School, University of São Paulo, São Paulo, Brazil 